Volume 2 Issue 2

December 2017

\title{
Building research capacity among Irish prehospital practitioners.
}

\author{
Alan M. Batt MSc $\mathrm{PhD}(\mathrm{c})$ \\ Irish College of Paramedics \\ Shane Knox PhD MSc HDipEMT AP \\ Irish College of Paramedics
}

\section{Recommended Citation}

Batt AM and Knox S. Building research capacity among Irish prehospital practitioners. Irish Journal of Paramedicine. 2017 Dec; 2(2).

This is an Open Access article distributed under the terms of the Creative Commons Attribution-Non-Commercial-ShareAlike 4.0 International (http://creativecommons.org/licenses/by-nc-sa/4.0/), which permits use, distribution, and reproduction in any medium, provided the original work and any attributes thereof are properly cited, are distributed under the same licence, and that the work is not used for commercial purposes.

Follow the Irish Journal of Paramedicine online at www.irishparamedicine.com, on Twitter (@irishjparamed) and on Facebook. 
PROFESSIONAL

\title{
Building research capacity among Irish prehospital practitioners.
}

\author{
Alan M. Batt MSc PhD(c), Shane Knox PhD MSc HDipEMT AP \\ Irish College of Paramedics \\ Correspondence: Alan Batt, Irish College of Paramedics. Email: vicepresident@irishparamedic.ie
}

Research can inform decisions about new technologies and treatments, and ambulance services can promote an evaluative culture. New advances are rapidly occurring in pre -hospital care, from staff with higher specialist skills, to new approaches to assessing and managing patients at scene. These new ways of working need to be assessed, to investigate if they deliver expected gains in terms of patient outcomes, cost savings, and relieving pressure on other parts of the healthcare system. Prehospital care practitioners have an important part to play in contributing to an evidence-based health service and improving patient care when it is most needed.(1)

Ambulance services and the pre-hospital/out-ofhospital care setting have historically been under-developed, and under-utilised, as areas of research. One study investigating trials in emergency medicine over ten years found that fewer than one in ten focused on pre-hospital care.

(2) Prehospital practitioners in general value research, more so when research is normalised, and when the research tasks are not burdensome.(3)

The 'National Prehospital Research Strategy' was published in 2008 (4), which aimed to gauge current levels of prehospital research activity in Ireland; ascertain the research strengths that exist in the Irish prehospital community; pinpoint the obstacles to high quality research in the prehospital arena; determine the building blocks for a national prehospital research culture; outline an implementation plan for the strategy; and, identify expected and measurable short and long-term outcomes of implementing the strategy. The characteristics of systems that facilitate research productivity include: the promotion of a research culture; mentoring by established scholars; communication with a professional network; rewards for research; and brokered opportunities.(5)

Almost ten years later, the development of research capacity within the practitioner cohort in Ireland has not progressed as much as hoped. A culture of research provides a supportive context in which research is uniformly expected, discussed, produced, and valued.(6) We posit that a culture of research does not yet exist among Irish prehospital practitioners.

The need for further education and training in research, and expanding existing opportunities for prehospital care practitioners is necessary. $(4,7)$ Research capacity building, the "process of individual and institutional development which leads to higher levels of skills and greater ability to perform useful research" (8) is essential not only to the development of the profession in Ireland, but to the ability to provide safe, evidence-based care to patients. The strategy document identified several barriers to prehospital research in Ireland. These include:

- $\quad$ Practitioners have little or no opportunity to develop research skills;

- Insufficient funding exists to support research projects;

- A research culture has not developed in prehospital care. (4)

The Irish College of Paramedics has to date supported, and encouraged, research, and scholarly activity by PHECC registered practitioners, members and non-members alike. The College has established international professional and research relationships with the Paramedic Association of Canada, the Turkish Paramedic Association, the College of Paramedics (UK and NI), the Australian and New Zealand College of Paramedics (in process), and many more organisations through both formal affiliations, collaborations, and membership of various committees and working groups. The College offers a free mentoring service for members designed to provide networking, and mentorship opportunities, in research, academia, and leadership.

The College publishes the Irish Journal of Paramedicine, a free, open-access peer-reviewed paramedicine journal, one of only a handful in the world. We deposit a copy of all research articles with Lenus, the Irish health repository, and Trinity College's eDepositIreland, ensuring that research findings are freely accessible to all practitioners.

Elsewhere, in Ontario, Canada, Alan is a member of a grassroots research-capacity building project known as the McNally Project for Paramedicine Research.(9) The McNally project was founded with the vision to address an identified gap - the provision of a group to allow for scholarly activities, and discussions, aimed at building capacity and contributions in paramedicine research. The project is a community, of and for, researchers and those hoping to become researchers. Published literature supports the importance of social interaction, and collegiality, among graduate students and faculty, to provide a strong foundation for subsequent research, and scholarly productivity.(10-12) McNally Project members have diverse areas of research interest, and are at varying stages of clinical and academic 
careers. The group is facilitated by an experienced faculty member, with a flat hierarchical structure employed.

This community and network has provided its' members with an 'academic centre', that while not directly related to their coursework, allows for the development of broader academic skills, citizenship and scholarly contributions. It should be noted that this initiative has not been without its challenges - the diversity of methods and approaches (considered both a strength, and a challenge), geographical location of meetings, and inconsistent attendance to name but a few. However, the establishment of such a grassroots initiative in Ireland is worth considering, and would likely present its own set of unique challenges in the Irish setting. Research is a collaborative endeavour and learning is inherently social; thus, such a group can reap great rewards for research capacity building. This initiative is also something the Irish College of Paramedics would be willing to support in whatever capacity it can.

Funding is another major challenge for Irish prehospital care practitioners wishing to undertake research. This is not unique to Ireland; the 'Canadian National EMS Research Agenda' recommended increased funding opportunities for EMS research infrastructure and studies, and the provision of scholarships for EMS providers, managers and physicians to take research-based graduate degrees.(7) The 'National EMS Research Agenda' in the USA also outlines that "funding is required to train new researchers and to help them establish their careers".(13) Research award schemes elsewhere have been well received, and have demonstrated increased research output by award recipients.(14,15) The establishment of research funding streams, and scholarships, for Irish practitioners are necessary to increase research capacity in the profession.

While we do acknowledge, and are encouraged to see, that an ever-increasing number of practitioners are undertaking bachelor and masters degree studies, in the University of Limerick, University College Cork, and University College Dublin, the dissemination of much of the practitioner-generated knowledge in these courses has not occurred. Practitioners have stated previously that appraisal of journal publications was less relevant to them as a continuing professional competency activity, again signalling the lack of a research culture we alluded to earlier.(16)

In an effort to begin to address this lack of dissemination, and engagement with the literature, this issue of the IJP sees the publication of research abstract proposals from BSc Paramedic Studies students from the University of Limerick. We are hopeful that this will begin to encourage ownership of research publications by practitioners. Indeed, we hope that we will see some of these proposals submitted to the journal as completed studies in the near future. Thesis abstracts for masters and doctoral studies can also be submitted for publication on the journal website. Peerreviewed publication output from PHECC-registered practitioners is sparse, and the presentation of practitioner-led research at scientific meetings is rare...this needs to change.

Petre and Rugg, in their book "The Unwritten Rules of $\mathrm{PhD}$ Research" liken undertaking a $\mathrm{PhD}$ to a cabinet-making apprenticeship.(17) Over the course of the apprenticeship, the apprentice learns and demonstrates that they have the skills required to build a cabinet, the final demonstration of which is a masterpiece cabinet. $\mathrm{In} \mathrm{ahD}$, the doctoral student learns and demonstrates that they have the skills required to be an independent researcher, the final demonstration of which is a thesis. We propose that this analogy is not just relevant to $\mathrm{PhD}$ research, but to all research and academic pursuits.

Practitioners with an interest in research need access to mentors who have successfully built masterpiece cabinets. They need to be given the opportunity to learn, and then demonstrate, the various steps in building a cabinet. It is important to note that not everyone needs to be able to build an entire cabinet by themselves; collaboration is recommended. Plenty of fine cabinets are being built right now by practicing paramedics and paramedic academics, all around the world, Finally, once the cabinet is built, it should be displayed by those who built it, for all to see and enjoy!

\section{References}

1. National Institute of Health Research. Care at the Scene Research for ambulance services [Internet]. 2016. Available from: http://www.dc.nihr.ac.uk/themed-reviews/Care at the scene final for web.pdf

2. Jones C, Isaacs C, Platts-Mills T. Randomized Trials in Emergency Medicine Journals, 2008-2011. Am J Emerg Med [Internet]. 2013;31(1):231-5. Available from: http:// pubmedcentralcanada.ca/pmcc/articles/PMC3494801/pdf/ nihms-389489.pdf

3. Pocock H, Deakin CD, Quinn T, Perkins GD, Horton J, Gates S. Human factors in prehospital research: lessons from the PARAMEDIC trial. Emerg Med J. England; 2016 Aug;33 (8):562-8.

4. Centre for Prehospital Research University of Limerick. A National Prehospital Research Strategy. Limerick; 2008.

5. Bland CJ, Center BA, Finstad DA, Risbey KR, Staples JG. A theoretical, practical, predictive model of faculty and department research productivity. Acad Med. 2005;80(3):225 -37 .

6. Hanover Research. Building a Culture of Research: Recommended Practices [Internet]. 2014 [cited 2017 Dec 4]. p. 1-33. Available from: http://www.hanoverresearch.com/ media/Building-a-Culture-of-Research-Recommended-

Practices.pdf

7. Jensen JL, Blanchard E, Bigham B, Dainty K, Socha D, Carter A, et al. Canadian National EMS Research Agenda. Ottawa; 2013.

8. Trostle J. Research capacity building in international health: Definitions, evaluations and strategies for success. Soc Sci Med. 1992;35(11):1321-4.

9. Batt A, Brydges M, Mausz J, Tavares W. A7. Building research capacity in paramedicine: the McNally Group. Irish 
J Paramed. 2017;2(S1):4.

10. Weidman J, Twale D, Stein E. Socialization of graduate and professional students in higher education: A perilous passage. In: ASHE-ERIC Higher Education Report. San Francisco: Jossey-Bass; 2001.

11. Perez RJ. A Conceptual Model of Professional Socialization within Student Affairs Graduate Preparation Programs. J Study Postsecond Tert Educ. 2016;1:35-52.

12. Gardner S. Faculty perspective on doctoral student socialization in five disciplines. Int J Dr Stud. 2010;5(June).

13. Sayre MR, White LJ, Brown LH, McHenry SD, National EMS Agenda Writing Team. National EMS Research Agenda. Prehospital Emerg Care. 2002;6(3 Suppl):S1-43.

14. Nasir S, Ahmed J. Incentives Matter: the Role of Research Productivity Award in Increasing Scientific Output of Pakistani Scientists. Sci, Tech Dev. 2013;32(3):251-6.

15. Miller DR, Wozny D. Research awards program of the Canadian Anesthesiologists' Society/Canadian Anesthesia Research Foundation: survey of past recipients. Can J Anaesth. 2007;54(4):314-9.

16. Knox S, Cullen W, Dunne CP. A national study of Continuous Professional Competence (CPC) amongst prehospital practitioners. BMC Health Serv Res [Internet]. 2015 Dec;15(1):532.

17. Rugg G, Petre M. The Unwritten Rules of PhD Research. Maidenhead: Open University Press; 2004.

Author contributions: $\mathrm{AB}$ and SK were joint authors of the manuscript, and both performed the final editing.

Source of support/funding: None.

Conflict of interest: $A B$ is Editor of the IJP, and VicePresident of the Irish College of Paramedics. SK sits on the IJP Editorial Board and is President of the Irish College of Paramedics.

Provenance and review: Commissioned, not peerreviewed.

This is an Open Access article distributed under the terms of the Creative Commons Attribution-Non-Commercial-ShareAlike 4.0 International (http:// creativecommons.org/licenses/by-nc-sa/4.0/), which permits use, distribution, and reproduction in any medium, provided the original work and any attributes thereof are properly cited, are distributed under the same licence, and that the work is not used for commercial purposes. Content copyright remains with the authors, who grant the IJP a licence to reuse and distribute. 